\title{
A FILOSOFIA DE MICHEL HENRY: UMA CRÍTICA FENOMENOLÓGICA DA FENOMENOLOGIA
}

\author{
José Luiz Furtado \\ Universidade Federal de Ouro Preto
}

\begin{abstract}
Abstrac: The aim of this paper is to show that Michel Henry's material phenomenology occupies a unique place in contemporary phenomenology. This will be done by comparing it mainly with Heidegger's philosophy and Husserl's. Material phenomenology is shown to be a project that invites phenomenology to rethink its foundations in the light of a new conception of the transcendental realm as a radical immanence of a Self that affects itself, constituting thus the insideness of egological life.
\end{abstract}

Keywords: Phenomenology; affection; intentionality; immanence; feeling.

Resumo: Este trabalho pretende ressaltar o lugar singular ocupado pela fenomenologia material de Michel Henry no horizonte da fenomenologia contemporânea, confrontando-a privilegiadamente com as filosofias de Heidegger e Husserl. O projeto da fenomenologia material, adiantamos, é o de convidar a fenomenologia a repensar de novo seus fundamentos à luz de uma nova concepção do campo transcendental como imanência radical de um Si que se afeta a si mesmo, e constitui, por esta via, a interioridade da vida egológica.

Palavras-chave: Fenomenologia; afetividade; intencionalidade; imanência; sentimento.

Michel Henry denomina sua filosofia, a partir do final dos anos 70, "fenomenologia material". Este conceito de materialidade fenomenológica irá caracterizar a singularidade e radicalidade do seu pensamento no seio da fenomenologia contemporânea, ou seja, o projeto de aprofundar o sentido do campo transcendental compreendido como essência da manifestação. Se a fenomenologia é ciência da essência dos fenômenos e não meramente descrição dos fenômenos, seria necessário, a fim de evitar uma incoerência tamanha que a invalidaria metodologicamente, que a própria essência da manifes- 
tação fosse, por sua vez, revelação de si. Que ela fosse, afinal, fenômeno. Mas, notadamente após Heidegger, sabemos que o fenômeno manifesta o ente, não o ser, considerado, no entanto, a essência da fenomenalidade. O ser se retira para o nada na medida em que se abre no ente. Como a luz - metáfora por excelência da compreensão ocidental da fenomenalidade - ele é o desejo do ente onde se reflete para, assim, iluminando outra coisa, cumprir seu destino essencial. Esta estrutura ontológica, segundo Henry, caracteriza toda a metafísica desde os gregos até a própria fenomenologia, e é por ele denominada "monismo ontológico". Trata-se de explorar e definir, segundo esta perspectiva dominante, uma só dimensão de manifestação fundamentada na exterioridade do horizonte de visibilidade constituído pelo "mundo", heideggerianamente compreendido, em oposição à noção husserliana de consciência intencional. Nesta compreensão da questão do sentido do ser onde se moveu desde sempre e exclusivamente a filosofia ocidental - segundo Michel Henry , o ser tem necessidade de uma mediação qualquer para vir a ser no ente, que a ele se opõe, o que ele é em si mesmo, isto é, o meio onde se forma sua ipseidade absolutamente originária.

Creio ser desnecessário demonstrar essa tese familiar aos leitores das obras de Heidegger, Merleau-Ponty e Sartre. Cada um dos filósofos mencionados tentou, a seu modo, desvencilhar-se da idéia de que a essência dos fenômenos apoiar-se-ia sobre um fundamento absolutamente transparente a si mesmo, através da construção de conceitos tais como "ser-no-mundo", "carnalidade" ou "cogito pré-reflexivo". A exterioridade ontológica e a obscuridade fenomenológica da essência dos fenômenos são dois temas que instigaram esses trabalhos situados entre os mais marcantes da fenomenologia nos últimos sessenta anos. ${ }^{1}$ Segundo as críticas endereçadas quase em uníssono a Husserl pelos autores citados, a afirmação do primado da consciência intuitiva, que pretende viver sempre na plenitude da presença originária do objeto por ela visado, conduziria à identificação entre visibilidade máxima e posse absoluta, permanecendo por isso tributária da arrogância da visão, desejosa de a tudo abarcar na transparência a si da sua própria origem. ${ }^{2}$ Por esta via a redução fenomenológica deixaria de lado a obscuridade do "irrefletido", do "invisível" ou "não-verdade" conforme o ponto de vista adotado, que constituiriam determinações intrínsecas da essência da fenomenalidade pura. Segundo o "monismo", o invisível se aloja no seio mesmo e na raiz da visibili-

\footnotetext{
${ }^{1}$ CHAMBON, R. Le Monde comme perception et réalité. Paris: Vrin, 1974, p. 295.

2 "Il importe de rester fidéle au principes des principes, à savoir que la clarté parfaite est la mesure de toute vérité et que les énoncés qui confèrent à leurs donnés une expression fidéle n'ont pas à se soucier d'arguments aussi raffinés qu'on voudra". HUSSERL, E. Idées Directrices pour une phénomélogie; introduction générale a la phénoménologie pure. Paris: Gallimard, 1950, p. 257.
} 
dade, não longe ou fora dela. Nesse sentido, afirma Sartre, "a presença é uma degradação imediata da coincidência, porque pressupõe a separação". ${ }^{3} \mathrm{E}$ continua: "a presença do ser a si” é a essência da presença, esta implicando, enquanto sua condição de possibilidade, "um descolamento do ser em relação a si”. ${ }^{4}$ Assim, o ser começa por se distanciar de si. O fenômeno resulta da degradação ontológica da coincidência da essência da aparência consigo mesma equivalente à sua projeção enquanto horizonte fenomenológico universal. A distância original é, na verdade, não o resultado de um processo ontológico, mas um poder de expansão em ato para fora de si, um naturante e não um naturado, uma constituição, não um constituido. Ser distancia. Se "é um fato que o ser se conhece através do homem ou por não importa qual consciência. É necessário que o ser seja à distância de si" ${ }^{5}$ A transcendência, afirma Sartrre radicalizando a noção de intencionalidade enquanto referência da consciência a qualquer coisa que ela própria não é: "é a estrutura constitutiva da consciência; isto é, a consciência nasce transportada sobre um ser que ela não é"6 e com o qual jamais poderá coincidir, ela é pura abertura ao ser-outro, ao ente. Assim a consciência não possui nenhuma interioridade que possa negar e assim sair de si mesma ou, ao contrário, nela se encerrar. Deste modo não há nenhum motivo para pensar a exterioridade ontológica, de fato, como uma dimensão da subjetividade humana e Heidegger pode afirmar que "a consciência... nem é a primeira a criar a abertura do ente, nem a primeira que dá ao homem o estar aberto para o ente. Pois, qual seria a meta, o lugar de origem e a dimensão livre para o movimento da intencionalidade da consciência se o homem já não tivesse sua essência na insistência"?.7 Em outra obra, no mesmo sentido, afirma o filósofo que "o mundo há de estar aberto já ek-staticamente para que se possam confrontar entes desde dentro dele". ${ }^{8}$

Assim a exterioridade deve ser pensada em sua pureza ao contrário de encerrá-la na subjetividade humana da qual ela seria - paradoxalmente - a estrutura interior. Deve ser pensada antes que sejamos lá. Por isso, afirma Michel Henry não há, rigorosamente falando, diferença entre as filosofias da consciência e do ser ${ }^{9}$, entre a experiência transcendental e a experiência do

\footnotetext{
${ }^{3}$ SARTRE, Jean-Paul. L'Être et le néant. Paris: Gallimard, 1982, 120.

${ }^{4}$ Sartre, ibid.., p. 119.

${ }^{5}$ I. MALVERNE, La condition de l'être, in Rev. Mét. Mor., janv. 1949, p. 42. Cit. in EM, 74. Grifado por mim.

${ }^{6}$ SARTRE, op. cit., p. 28.

${ }^{7}$ HEIDEGGER, M. Introdução à metafísica. Trad. Carneiro Leão, Rio: Tempo Brasileiro, 1969, p. 72.

8 HEIDEGGER, M. Lo ser y el tiempo. Trad. José Gaos. México: Fondo de cultura económica, 1987 , p.395.

${ }^{9}$ Cf. L'Essence de la manifestation. Paris: PUF, 1986, § 09.
} 
mundo se, através da intencionalidade ou da transcendência, trata-se da explorar a mesma dimensão ontológica da fenomenalidade onde o conteúdo revelado se constitui pela alienação de si da essência que o revela e que vem a ser o objeto da elucidação fenomenológica.

A promoção de uma nova esfera de ser e de existência caracterizada pela imanência absoluta do ego a si mesmo, irá permitir à fenomenologia de Michel Henry ultrapassar o monismo ontológico revelando, criticamente, sua principal deficiência: a impossibilidade de justificar a referência fundamental da problemática à subjetividade humana, seja como ego puro ou Dasein, se para evitar o psicologismo ou a entificação - o ego é identificado a uma pura essência ou possibilidade e o Dasein ao "lugar tenente do nada" ${ }^{10}$

No tangente á Husserl as estruturas transcendentais descritas depois da redução fenomenológica não são as desse ente intra-mundano chamado homem. Trata-se, ao contrário, de uma consciência "sem homem" como afirma Derrida de um puro eidos, uma pura possibilidade implicada pela análise eidética do conhecimento racional, um simples "vestígio", enfim, sem nenhuma efetividade. ${ }^{11}$

Assim a crítica de Husserl a Heidegger se explica justamente em função dessa compreensão eidética da subjetividade transcendental como pura possibilidade para a qual nenhuma facticidade mundana importa. De fato Husserl viu no Dasein heideggeriano um desvio antropologista e no ser-nomundo uma mundanização. Apesar de Heidegger insistir, ao longo de quase todas suas obras, que toda investigação acerca da essência do homem pressupôs sempre, ao longo de história da filosofia, uma certa interpretação do ente, sem investigar anteriormente a verdade do ser considerada em sua forma purificada.

Toda a determinação da essência do homem que pressupõe já, quer ela o saiba ou não, a interpretação do ente sem colocar a questão relativa à verdade do ser é metafísica, o Dasein não permanecendo jamais exterior à essencialização do ser no ente. A abertura do mundo só se completa se o Dasein está, por sua vez, e a partir da sua própria existência, para ela aberto. O ser do homem "participa em si mesmo da constituição do ser"12, ele é a essência do próprio fato de algo ser (Das-sein). O homem, diz ainda Heidegger, "mantém livre o lugar para o totalmente outro do ente, de tal modo que, em sua abertura, se possa dar algo assim como pre-sença $(\text { ser })^{113}$. E, em outra obra

\footnotetext{
${ }^{10}$ HEIDEGGER, M. Sobre o problema do ser. Trad. Ernildo Stein, São Paulo: Duas Cidades, 1969, p. 54.

${ }^{11}$ DERRIDA, J. A voz e o fenômeno. Rio: Zahar, 1978, p. 95

12 HEIDEGGER, M. Sobre o problema do ser. Trad. Ernildo Stein, São Paulo: Duas Cidades, 1969, p. 40

${ }_{13}$ Idem, p. 54-55.
} 
afirma, no mesmo sentido: "a essência do homem é essencial para a verdade do ser". ${ }^{14}$

Mas, se a fenomenalidade da "ek-sistência" é idêntica à da abertura do ser, então, porque a segunda não se esclarece senão através do homem? A introdução do Dasein humano aqui mascara, segundo M. Henry, o verdadeiro problema. A abertura prévia pressuposta pelo que é aberto, não é a abertura da "ek-sistência", mas do aberto em si mesmo: "não a abertura que ele torna possível, mas a que o torna possível", ou seja, "o processo transcendental que projeta diante de, que projeta o Aberto ele próprio". ${ }^{15}$ Característica dessa maneira oblígua de inserir o homem na problemática da determinação interna da abertura do ser, é a passagem - citada a seguir - da "Introdução à metafísica" onde Heidegger afirma ser a possibilidade de questionamento do ente, ou seja, a "investigabilidade" do seu ser, experimentada por nós, não como modo da reflexão sobre o fenômeno pondo-o em questão através da dúvida, mas como uma determinação ontológica da presença que se realiza manifestando-se no próprio ente". "A investigação abre apenas o espaço para o ente poder revelar-se nessa sua investigabilidade", propriamente falando, previamente constituída. A atividade humana de investigação, vista a partir do seu fundamento ontológico se reduz à "abertura para o poder não ser o que é e tal como é"16, que pertence à essência da fenomenalidade como tal.

A ultrapassagem do campo ontológico monista exigirá pois a prática de uma redução bem mais radical do que a husserliana e heideggeriana, e cujo precursor Michel Henry encontrará, surpreendentemente, em Descartes. Segundo nosso autor Descartes faz incidir sobre toda esta constelação unitária formada pela luz pura da ratio, do intueri, e o conjunto dos seres que ele permite conhecer, mesmo com evidência,o golpe de uma redução radical. ${ }^{17}$ Esta redução não seria possível se a compreensão cartesiana do horizonte ontológico do conhecimento não se fizesse fenomenológica em um sentido

\footnotetext{
${ }^{14}$ HEIDEGGER, M. Lettre sur I'humanisme. Trad. R. Munier. In: Question III. Paris: Gallimard, 1966, p. 124.

${ }^{15} \mathrm{Cf}$. Généalogie de la psychanalyse. Le commecement perdu. Paris: PUF, 1985, p, 115.

${ }^{16}$ HEIDEGGER, M. Introdução à metafísica, p. 57.

17 Na "Regra I" Descartes diz da luminosidade transcendental da "Sapientia universalis", que "ela permanece sempre una e sempre a mesma, por mais diferentes que sejam os objetos aos quais ela se aplica, e não recebe nenhuma mudança desses objetos, assim como a luz do sol não varia conforme a variedade das coisas que ela ilumina". (Regras para a direção do espírito. Trad. Artur Mourão. Porto: Edições 70, 1989, p. 12) Ver também, sobre o significado transcendental da luz em Descartes: FOUCAULT, M. O Nascimento da clínica. Trad. Roberto Machado, Rio, Forense-Universitária, 1977, p. XII. "A luz, anterior a todo olhar, era o elemento da idealidade, o indeterminável lugar de origem em que as coisas eram adequadas à sua essência e a forma segundo a qual estas a ela se reuniam através da geometria dos corpos; atingida sua perfeição, 0 ato de ver se reabsorvia na figura sem curva, nem duração, da luz".
} 
mais radical do que as fenomenologias de Husserl e Heidegger, a análise partindo justamente da indiferença da pura luz em relação a tudo o que ela esclarece, isto é, a todo ente, e o ver da "ratio" (o "intueri" do "intellectus") enquanto, precisamente, "ver-que-se-lança-na-luz". ${ }^{18}$

Trilhando esse caminho aberto pela redução transcendental, da visão racional às suas condições ontológicas de possibilidade, "o evidente", isto é, "o ser aparente tal como aparece, tomado precisamente em sua pura aparência e reduzido a ela”, é falso. E isto porque a própria evidência, e toda visão efetuada a partir da visibilidade do mundo, sensível ou, ao contrário, puramente intelectual, é falsa. Afastando, através da dúvida metódica, a certeza de tudo o que se propõe como objeto, Descarte afasta do campo da investigação, com um só golpe, o horizonte de visibilidade aberto do mundo e o princípio da sua projeção. Por esta via a própria luz resulta, em si mesma, falaciosa, na medida em que não se esclarece por si mesma, em que não revela o essencial: o princípio da manifestação da essência da manifestação do horizonte fenomenológico do mundo. Assim resulta, para Michel Henry, que "a edificação interior da cogitatio", reconhecida por Descartes graças à dúvida radical que supera qualquer evidência, "desqualifica a visão pura da qual fala Husserl"19 fazendo surgir a vida egológica em sua realidade e anterioridade a toda reflexão a ela referida, tal como constituída pela afetividade. Sem nos aprofundarmos por hora no sentido desta interpretação sui generis do cogito, que nos desviaria do essencial, façamos notar tão somente que o pensamento visado pelo cogito como fundamento absoluto da verdade não é o pensamento pensado e projetado diante da visão objetivante de um pensamento pensante que já é, nesse distanciamento temporal da retenção. Era para Husserl segundo o qual "o tipo de ser próprio do vivido implica que o olhar de uma percepção intuitiva pode se dirigir sobre todo vivido real e atual (vivant) enquanto presença originária". ${ }^{20}$

Mas esta apreensão intuitiva não é, nem pode ser, originária e efetiva. Ela é impotente para constituir e determinar a realidade (eu posso) da vida egológica enquanto ipseidade e imanência na medida em que depende da projeção distanciante da transcendência temporal. É o que mostrava segundo Henry "este mais belo livro de todos os tempos", a saber, as "Lições sobre a consciência imante do tempo". ${ }^{21}$ Nesta obra assistimos o desesperado esforço

\footnotetext{
18 Descartes et la question de la technique, in Le Discurs et sa méthode, N. Grimaldi et J.-L. Marion (Org.), Paris: PUF, 1987, p. 285-302, p. 291.

${ }^{19} \mathrm{Cf}$. Phénoménologie matérielle. Paris: PUF, 1990, p. 66. Grifado por mim.

${ }^{20} \mathrm{Cf}$. Idées, op. cit, § 45.

${ }^{21}$ Cf. Leçons pour une Phénoménologie de la conscience intima du temps. Trad. Dussort. Paris: Gallimard, 1964.
} 
do filósofo para se acercar, a partir da fenomenalidade aberta por "este meio universal que porta em si todos os vividos, mesmo os que não se caracterizam como intencionais", ${ }^{22}$ de uma esfera ontológica original cuja revelação se recusa obstinadamente a se deixar reduzir aos princípios internos da visão intencional.

O ego é bem esta experiência de si reclamada e ocultamente visada pela problemática da elucidação fenomenológica da essência da manifestação. Mas ela não depende da intencionalidade ou de qualquer tipo de visão, como Descartes teria demonstrado. Uma revelação imanente sendo necessariamente presença a si, não poderia ser senão invisível, pois nenhuma presença visível no horizonte do mundo ou da consciência pode ser presença de si a si: ver é ver à distância de si. Uma revelação imanente, como afirmará Henry, sendo uma experiência interna, revestirá necessariamente uma forma monádica. "É na estrutura eidética da verdade originária”, pensada em seu fundamento ontológico enquanto revelação imanente e interior de si, constituída pela afetividade, "que se enraíza a ipseidade do ego". ${ }^{23}$ O ser de o "eu sou" é uma experiência interna ao próprio ser.

É então o sentido da imanência que deveremos precisar daqui por diante especificando primeiramente que se trata, ao mesmo tempo, de uma dimensão ontológica e fenomenológica. Primeiramente a imanência não é uma dimensão oposta à transcendência característica do horizonte aberto do ser, como pensa Sartre afirmando estar a essência dos fenômenos situada além da fenomenalidade. Ela seria, nesse sentido, "transfenomenal". ${ }^{24}$ Ao contrário, Michel Henry afirma a existência de uma outra dimensão efetiva da fenomenalidade que comporia, juntamente com a dimensão ek-stática do mundo, a totalidade ontologicamente compreendida da manifestação. A essência dos fenômenos não se opõe à fenomenalidade que ela torna possível, não está além ou aquém da manifestação que é sua obra. Ela se manifesta em outro lugar, de uma outra forma, de forma imanente, através da afetividade da vida, que iremos expor em seguida, examinando, em particular, as relações entre a fenomenologia de Henry e a de Husserl. Pois, há conforme o radicalismo fenomenológico da filosofia de Michel Henry, uma manifestação determinada da essência da manifestação do mundo e dos fenômenos: "por detrás ou além desses dois tipos de manifestações essenciais, não resta

\footnotetext{
${ }^{22}$ Cf. Idées, op. cit., p. 287, sublinhado por nós.

${ }^{23} \mathrm{Cf}$. Essence de la manifestation, § 7.

24 "Como 0 ser dos fenômenos pode ser transfenomênico ?", escreve Sartre afirmando ser essa a principal pergunta a que o Ser e o nada pretendia dar uma resposta. Op. cit., p. 28.
} 
nada" ${ }^{25}$ A essência do ser não é para Michel Henry, ao contrário de Heidegger, a "não-verdade": "a essência do ser é a manifestação de si”26.

\section{II}

Os esforços filosóficos para fazer coincidir a constituição do sujeito com as manifestações da sua vida no fluxo interior da consciência, são conhecidos, desde Descartes. A genialidade de Husserl, segundo Michel Henry, consistiu em ter tido "mais que todo outro filósofo, a consciência das dificuldades internas do seu pensamento". ${ }^{27}$ Prova disso é o reconhecimento, por Husserl, do absurdo da tese que afirma a inconsciência da fase inicial do fluxo temporal das vivências. ${ }^{28}$ Para Husserl os momentos da temporalidade originária da consciência constituem um contínuo homogêneo unificado sob a forma permanente de uma consciência atual. "A consciência é, necessariamente, ser-consciente em cada uma das suas fases". ${ }^{29}$ Mas Husserl descarta também a afirmação de que a consciência, "desde a sua origem e em sua constituição mais íntima", seja, não simplesmente "consciência representativa dos conteúdos passados" que a afetam interiormente (solução kantiana da apercepção), mas, além disso, consciência "no passado". ${ }^{30}$ Husserl pressentiu que isso equivaleria, diz M. Henry, a "mettre toute notre vie au passé". ${ }^{11}$ Mas, apesar dessa dificuldade, permaneceu estabelecendo a primazia ontológica da doação extática da percepção intuitiva das vivências, ainda que esta pressuponha, rigorosamente, a impressão originária e sua doação imanente. ${ }^{32}$ Para Husserl a percepção imanente (no sentido que o conceito de imanência opera em Husserl) da vivência se faz a partir de uma evidência apodítica cujo conteúdo revelado coincide com o ser próprio da subjetividade efetiva.

É, pois, na atualidade da vida, no presente vivo que devemos encontrar o ser da consciência, atualidade que não pode ser senão presença imanente a si anteriormente a toda projeção da vivência no horizonte retencional aberto temporalmente da consciência. Entretanto, em que pese suas intuições mais sutis, enquanto o fluxo das vivências é um elemento do processo trans-

${ }^{25} \mathrm{Cf}$. Philosophie et phénoménologie du corps, p. 164.

${ }^{26} \mathrm{Cf}$. Essence de la manifestation, p.173.

${ }_{27} \mathrm{Cf}$. Phénoménologie matérielle, 52.

${ }^{28}$ As vivências não podem ser 0 eco interior das coisas porque senão recairíamos no psicologismo e no empirismo e a consciência não poderia exercer sua função transcendental de constituição.

${ }^{29} \mathrm{Cf}$. Idées, op. cit., § 24, p. 78.

${ }^{30} \mathrm{CHAMBON}$, op. cit., p. 98.

${ }^{31}$ Phénoménologie matérielle, p. 52.

32 A propósito da crítica de Michel Henry a Husserl ver: Daniel Giovannangeli. La passion de l'origine. Paris: Galilée, 2002. 
cendental de constituição, ele requer, justamente porque este processo deve ser fenomenologicamente elucidado, a possibilidade da sua doação originária, intuitiva, em pessoa Por isso Husserl afirma que "o tipo de ser do vivido" requer que ele seja "perceptível, em princípio, sob o modo da reflexão"33 tal como ele já era ates desse olhar retroativo. Sem isto a redução nos conduziria a um nada de ser, a um fluxo caótico. Por isso Husserl acrescenta que a preensão do vivido retido pela vivência atual não provoca nenhuma alteração essencial no primeiro. O vivido permanece "tal como ele era já de modo irrefletido"34. Mas como se pode saber em que consistia a vivência antes que o olhar intencional recaísse sobre ela se o que se situa fora da intencionalidade não se manifesta e afinal, nada é? Para Sartre, que pretende eliminar do pensamento de Husserl toda forma de referência possível a uma dimensão não intencional da subjetividade, mesmo sob o modo de um pressentimento, é a própria "consciência quem recusa" esse "ser híbrido" da "hylé husserliana" que não "saberia fazer parte do mundo" 35 , nem como conteúdo ôntico - nós não percebemos sensações mas coisas - nem como matéria transcendental dos seus atos. Mas, por que uma questão de princípios estabeleceria que um passo dado fora da esfera da intencionalidade nos conduziria fora do aparecer e do ser? De fato, é “a própria consciência”, e não uma decisão filosófica qualquer - mesmo metodológica - que recusa dar abrigo a alguma coisa como uma impressão puramente imanente, já que consciência quer dizer distanciamento e alienação de si, de modo que ela não poderia exibir em seu horizonte aberto nada que se caracterizasse por uma interioridade radical. Inclusive porque este ser impressional imanente se propõe, na fenomenologia de Husserl, como a componente "real" da consciência e como seu último fundamento, como o resíduo irrecusável da última redução transcendental. Mas a consciência que recusa a imanência da doação originária dos dados impressionais é a consciência concebida a partir dos princípios do monismo fenomenológico, isto é, reduzida à pura transcendência da sua essência intencional. Não é então, propriamente falando, na consciência como tal, mas na consciência fenomenologicamente concebida, que se encontra o fundamento da recusa em conferir uma consistência ontológica autônoma aos dados materiais do fluxo subjetivo das vivências.

Partindo da concepção, de origem cartesiana, que identifica o ego à efetividade de um pensamento que apreeende a si mesmo na efetuação imanente do seu agora, Derrida encontrará em Husserl a refutação mais radical

\footnotetext{
${ }^{33} \mathrm{Cf}$. Idées, op. cit., p.147.

${ }^{34}$ Idem, 146.

35 Sartre, op. cit., p. 28.
} 
daquela posição "metafísica dogmática". Na medida em que o olhar intencional só pode captar o que ele projeta à distância de si mesmo, o em si que ele arranca da obscura imanência do agora para retomá-lo no distanciamento projetado pela retenção, do seu já-ter-sido, essa sua própria dinâmica exige que o ego, cuja essência é a ipseidade, seja suprimido da problemática como uma miragem fenomenológica. Ou essa miragem não será o resíduo inapreensível de uma redução que, visando apreender uma esfera de ser absoluta, ${ }^{36}$ diante da evidência de uma intuição apodítica, falha em sua empreitada justamente porque esse absoluto se subtrai eternamente à luminosidade do mundo cuja essência é, justamente, a exterioridade a si do ser?

$\mathrm{O}$ absoluto, o que não pode mais ser atingido pelo golpe de nenhuma redução, por mais radical que ela seja, o dado absoluto, quando já foram excluídos todos os modos da percepção, mesmo a percepção mais evidente, isto é, a intuição imanente (imanência tomada aqui no sentido que lhe empresta Husserl) das vivências, é o conteúdo impressional puro, a sensação, ou melhor, seu modo de surgir e vir a si originariamente em e por si mesma no fluxo temporal, seu vir-a-ser no agora. Mas esta fenomenologia do presente vivo, da presença não intencional, que suspendeu, portanto, a possibilidade mesma da percepção, permanece prisioneira dos seus próprios pressupostos metodológicos, permanece, todavia, uma fenomenologia da percepção. ${ }^{37}$

Por esta via, considerando por eles mesmos esses "dados absolutos", esses "componentes reais" da consciência como um todo, mas não intencionalmente incluídos na noesis, estas impressões sem as quais "a consciência nada seria", 38 e que constituem a consciência em sentido originário, qual é o modo originário da sua manifestação? Cedendo a palavra à Michel Henry:

não é enquanto impressional (impressionnelle) que a impressão é dada, não é enquanto sentida, em seu auto-sentir e por ele, que o sentir é dado. É enquanto se encontram presentes em uma consciência do agora, uma consciência do presente batizada "consciência originária", percepção originária, percepção interna, percepção imanente, sentir originário, consciência interna do tempo, etc. ${ }^{39}$

\footnotetext{
36 "Fundar absolutamente o conhecimento não é possível senão na ciência universal da subjetividade transcendental enquanto único ser existente de maneira absoluta". Logique formelle et transcendantale. Trad. Suzanne Bachelard, Paris: PUF, I965, § I03, p. 361.

${ }^{37}$ Ver GRANEL, G. Le sens du temp set de la perception chez Husserl. Paris: Gallilé, 1968, p. 94.

${ }^{38} \mathrm{Cf}$. Leçons pour une phénoménologie de la conscience intime du temps. Paris: PUF, 1964, p. 125.

${ }^{39} \mathrm{Cf}$. Phénomenológie matérille, p. 35.
} 
A questão é absolutamente crucial. Se a consciência é o fundamento absoluto ao qual retornamos seguindo os preceitos metodológicos da redução que nos aprofunda na esfera das doações imanentes (no sentido de Husserl), e dos dados absolutos, deveria ser possível conferir a ela o mesmo tratamento fenomenológico emprestado às sensações. Mais precisamente, a redução transforma em dado absoluto a vida mesma do ego puro tomado em sua ipseidade. $\mathrm{O}$ desenvolvimento da problemática nos conduz à apreensão da possibilidade da existência de uma consciência afetada por si mesma sem a mediação, portanto, de nenhum ato objetivante, da projeção de nenhum horizonte ou distância, numa perfeita imanência a si. Numa palavra: uma essência ou dimensão não intencional da consciência. Ora esta doação imanente existe e caracteriza eideticamente a manifestação originária do sentimento, o que o próprio Husserl foi o primeiro a pressentir, malgrados os pressupostos monistas do seu pensamento e a decisão de tudo reduzir à estrutura fenomenológica da consciência intencional, por ele considerada universal, como vimos. "Nas Investigações Lógicas", apontando para a possibilidade da existência de sensações puramente afetivas Husserl afirma que "prazer e dor podem persistir mesmo quando os caracteres de atos edificados sobre eles já desapareceram ... em lugar de figurar como representante de uma qualidade do objeto a excitação é simplesmente relacionada ao sujeito que a sente". ${ }^{40}$

Por esta via Husserl reconhece a autonomia da revelação do sentimento diante da revelação do que se supõe ser sua motivação noemática, numa percepção ou intuição. $\mathrm{O}$ objeto em presença do qual o sentimento se produz nada tem a ver com a determinação ontológica da revelação do sentimento em e por si mesmo. Para uma fenomenologia da imanência, tal objeto é desprovido de importância porque nada esclarece da essência do sentimento que dá a sentir o que ele compreende - a saber, seu conteúdo imanente - na e pela afetividade. Esta revelação, pode ser, permanece por ser esclarecida. Mas, na medida em que se apóia sobre a intencionalidade depende inteiramente da revelação imanente do sentimento a si, dependência que se constitui a partir de uma anterioridade ontológica radical. Porque o sentimento de prazer não nos é jamais dado pela coisa prazerosa considerada em si mesma, como qualidade objetiva, isto é, em seu caráter noemático, do mesmo modo como nenhuma cor jamais existiria nas coisas, na ausência dessa "vibração interior" que constitui, para Kandinsky, a sua verdadeira e efetiva essência: "deve haver

${ }^{40} \mathrm{Cf}$. Recherches Logiques. T. 2: Recherches pour la phénoménologie et la théorie de la connaissance. Paris: PUF, 1962, p. 395. 
vibração interior da alma. Sem isto não existe, não pode haver obra de arte" ${ }^{41}$

A concepção do sentimento como "estado psíquico" causado pela presença de um ente no nosso campo sensível, é ingênua e pré-crítica, porque o ente não pode nos afetar senão enquanto se fenomenaliza, no horizonte aberto do mundo, como objeto, justamente, sensível. "É o objeto, não o ente, afirma Michel Henry, que nos afeta". Mas objeto, quer dizer, "isto na direção de que a existência se ultrapassa e é por ela constituído" 42 de tal maneira que o sentimento por ela experimentado em presença deste objeto pertence ao processo imanente, à realidade interna própria do ato de constituição das condições transcendentais da sua vinda na luminosidade do mundo. Assistimos assim a uma completa inversão dos dados das teorias clássicas da sensibilidade ( notadamente a de Kant), inversão cujo caráter paradoxal não passou desapercebido a Michel Henry: ${ }^{43}$ "Não é o que chega que determina a afetividade e sim a afetividade que torna possível a vinda do que advém"44 isto é, o ente na condição de fenômeno - e, como tal, determina afetivamente sua manifestação.

Esta determinação afetiva constitui o fundamento de uma estrutura universal e apriórica que atinge tudo o que é suscetível de nos afetar, de nos tocar, de qualquer forma, de, numa palavra ser recebido numa intuição como objeto. Trata-se da "determinação ontológica estrutural da afecção pela afetividade", 45 isto é, do fato de que a afecção pelo ente não é possível se não na medida em que o ato de transcendência que projeta o horizonte da sua receptividade afeta-se a si mesmo na imanência do seu pathos originário. Nenhum ser possível poderia nos fazer sentir o que quer que seja se o conteúdo afetivo desse sentimento tivesse que nos ser aportado do exterior, como efeito de uma causa ou mesmo como significação constituida. Nos dois casos, quer a significação tomada como noema na correlação intencional originária noético-noemática, quer o próprio "efeito psicológico", ambos pressupõe a afecção pura, ou seja, "o ser dado ele próprio considerado em sua possibilidade intrínseca e em sua realidade própria”. 46

\footnotetext{
${ }^{41}$ Cf. "La peinture em tant qu'art pure". In: Regards sur le passé, Paris: Hermann, 1974, p. 196. Ver a propósito, Michel Henry, Voir L'Invisible: sur Kandinsky. Paris: François Bourin, 1988.

${ }^{42} \mathrm{Cf}$. Essence de la manifestation, § 55, p. 610.

43 "Sensibilidade e Afetividade (em maiúscula no original) entretém entre si uma relação paradoxal, ao mesmo tempo antinômica e fundadora ... a Afetividade fundamenta a sensibilidade" (Incarnation, p. 329) ao mesmo tempo que a exclui.

${ }^{44} \mathrm{Cf}$. Essence de la manifestation, § 55, p. 611.

$45 \mathrm{Idem}, \mathrm{p} .611$.

${ }^{46}$ Idem, §17, p. 638.
} 
Certamente, os sentimentos nos são dados duas vezes e, por isso, se distinguem dos outros atos intencionais ${ }^{47}$, ao relacionarem-se ao mesmo tempo a um objeto e uma tonalidade afetiva do sujeito e, conforme a pesquisa se encaminha para uma dessas vias, pode desembocar na análise da constituição da percepção afetiva ou remeter ao encontro interior do sujeito consigo próprio, com a imanência do fluxo da sua vida afetiva. Esta última via é a seguida por Husserl quando afirma, despojando-se das suas intuições iniciais sobre o caráter imanente dos dados hiléticos, que "o prazer ou desprazer se dirigem sobre o objeto representado e, sem dúvida, sem esta orientação", que é justamente a intencionalidade, "não poderiam absolutamente existir". ${ }^{4}$

Michel Henry refuta radicalmente esta tese conforme a qual o sentimento visa, se dirige para ou é provocado por qualquer coisa, por mais que esta afirmação esteja enraizada no senso comum. Segundo o autor, "quanto mais um pensamento é superficial e inverso à ordem verdadeira das coisas, mais extensa é a audiência que lhe será assegurada" 49 Assim, se é verdade que "ninguém jamais viu um sentimento", 50 não é menos verdadeiro que o "sentimento jamais fez ver nada". ${ }^{51} \mathrm{O}$ ser do sentimento no seu original aparecer a si é, de fato, "absolutamente cego" 52 , nem visível nem vidente. Mas, de fato, introduzida desta forma a elucidação henriana da essência do sentimento pode parecer infundada porque associamos comumente afetividade e sensibilidade. Conforme uma expressão concisa de " $L$ 'Essence de la manifestation", a afetividade nos doa o que "se sente sem ser por intermédio de um sentido"53. Por isso "nenhum sentimento pode ser sentido", porque não pode ser o objeto de um ato sensível, como a rugosidade da madeira ou calor do fogo são sentidos pelo tato. $O$ sentimento não pode ser sentido na medida em que não pode ser a revelação de um conteúdo transcendente, em que é, e só pode ser compreendido como revelação de si, do seu próprio conteúdo afetivo,

\footnotetext{
${ }^{47}$ Pode ocorrer que a excitação vivida do prazer provocado em nós pela experiência de um fato alegre qualquer seja tomada por um olhar que se volta sobre ela e a "modifica" (Idées, § 77).

${ }^{48} \mathrm{Cf}$. Recherche logique, § 15a.

${ }^{49} \mathrm{Cf}$. Essence de la Manifestation, $\S 55$.

50 A expressão da dor, por mais que convoque nossa simpatia e solidariedade, não é a própria dor e sim sua representação através da alienação da distância do mundo de onde o outro nos vem ao encontro como um objeto. Em todo caso esta dor presente, a título de significação das expressões faciais onde se encarna, pelo menos, na minha percepção do outro, é, em princípio, dubitável. Enquanto a dor efetivamente sentida é absolutamente inquestionável. Um sentimento vivido na imanência da sua afetividade, ao contrário de uma idéia, da visão de uma paisagem ou da verdade um juízo, não pode ser, absolutamente, compartilhado. Se pudesse sentir o que um outro sente, eu seria o outro e o outro seria eu. 0 sentimento se ergue no ser a partir da partição insondável da vida monádica em diferentes ipseidades.

${ }^{51}$ Essence de la manifestation, p. 680.

52 Idem, p. 726.

53 Idem, § 52, p. 659.
} 
quer este conteúdo seja atribuído, projetado ou incorporado na estrutura objetiva de uma experiência sensível ou não.

Mas, mais do que uma diferença, afetividade e sensibilidade guardam entre si uma relação de fundamentação. Há uma "fundamentação imanente da sensibilidade na afetividade" de tal modo que, por exemplo, o olhar que não pode ver a si mesmo vendo, porque mesmo sua mais perfeita imagem especular não vê, se sente vendo e nesse sentir si mesmo se constitui propriamente como ato efetivo reunindo-se ao poder do egológico que o efetua. "Sentimunus videre", afirma Descartes citado por Henry. ${ }^{54} \mathrm{O}$ impossível ver que se vê vendo se afeta e, por via desta afetividade, se conhece interiormente como ato de um eu que vê.

Então o sentimento eideticamente concebido não pode absolutamente entreter nenhuma relação com qualquer objeto e defini-lo como sentimento não intencional, tal como procede Husserl a propósito dos dados hiléticos da consciência, não tem sentido. Se admitirmos, juntamente com o fundador da fenomenologia, a existência de sentimentos intencionais e não intencionais, então a essência do sentimento deveria ser indiferente à forma da intencionalidade. Para Henry, ao contrário, a distinção entre o sentimento "vivido" mas não percebido, isto é, a vivência no momento em que se efetua, e esse mesmo sentimento percebido, o sentimento enquanto matéria impressional da noesis, no primeiro caso, e do noema, no segundo caso, é ontológica. A visada da consciência não produz uma modificação, precisamente, intencional no sentimento na medida em que é tematizado. Ela não pode justamente introduzir nenhuma modificação no ser original do sentimento, em sua tonalidade afetiva por exemplo, porque nenhuma tonalidade afetiva é capaz de se manifestar enquanto tal, em sua efetividade, diante do olhar objetivante da própria consciência. A consciência da dor, por mais adequada e verdadeira que seja, por mais rigorosamente construída, não é jamais dolorosa. Um abismo ontológico separa a doação imanente do sentimento a si através da auto-afecção da sua essência e sua representação objetivante. Se um conteúdo representativo pode se propor a nós a partir do mundo como representação, por exemplo da dor, isto se deve ao fato da doação prévia da dor a si mesma na essência da sua afetividade. Só através da estrutura monádica da vida constituída pela afetividade alguma coisa como um Si pode existir, só através dela qualquer coisa como uma ipseidade pode surgir, porque o conteúdo afetante e o afetado na auto-afecção, são rigorosamente o mesmo.

Assim quer a consciência reflexiva modifique ou não os sentimentos sobre os quais se volta, e independentemente da consideração dessa modifica-

\footnotetext{
${ }^{54} \mathrm{Cf}$. Généalogie de physicanalyse, p. 56 e ss.
} 
ção potencial, ela é, por uma razão de princípios, incapaz de exibi-los enquanto tais. ${ }^{55} \mathrm{~A}$ suposta exibição do sentimento modificado não é, precisamente, revelação da modificação na estrutura interna do sentimento, em sua tonalidade afetiva, tal como ela se revela na imanência do seu afetar-se a si mesma, mas exibição da impossibilidade, para o pensamento, de apreender o sentimento qualquer que ele seja, em seu ser próprio, apenas referindo-se ao simulacro vazio por ele posto no lugar do que não pode, em princípio, objetivar-se jamais. O sentimento não é nem pode ser modificado durante o processo da sua objetivação porque esse processo é um processo de constituição, uma síntese ativa e o sentimento é essencialmente "pathos".

A este propósito a intervenção perspicaz da fenomenologia material permite dissipar todo contra-senso relativo ao estatuto antológico da reflexão que se volta para a sensação vivida fazendo dela o objeto de uma intuição: "o olhar objetivante é responsável pela modificação da alegria e em geral de todas as tonalidades afetivas, não enquanto ele as faz aparecerem como sensações modificadas na objetividade que ele suscita e onde as projeta. Ao contrário a reflexão modifica a vivência afetiva originária justamente porque, quer seja originária ou modificada ela será, em princípio, incapaz de se manifestar "no meio ontológico da objetividade". Assim a reflexão não altera a vivência originária. O que surge como seu resultado, se ela pretende apreender a vivência "em carne e osso", em pessoa, é a determinação afetiva interior de um ato malogrado, de uma intencionalidade não preenchida, exprimindo o problema do conhecimento e sua angústia na medida em que não pode se acercar do seu objeto, em que a afetividade lhe escapa definitivamente, como tal. $^{56}$

Entretanto o sentimento não possui autonomia ontológica. Sua essência é afetividade e afetividade quer dizer em Michel Henry auto-afecção em que afetante e o conteúdo afetado são a mesma coisa. É então o ser si mesmo, ou seja, a ipseidade da vida egológica que abre o espaço onde a afetividade se constitui precisamente a partir da ipseidade, como unidade imanente do ser, de modo que nossos sentimentos, mesmo na eterna passagem de uma de suas tonalidades a outra, em seu fluir incessante, do sofrimento à alegria e vice versa, não rompe a unidade interior da vida neles. Daí a necessidade de pensar uma "temporalidade patética", isto é, onde a afetividade da vida do ego que se transforma não acarreta a separação de si como, segundo Michel Henry, Maitre Eckart entreviu. "O que passou a quinze mil anos não está mais

${ }^{55} \mathrm{Cf}$. Essence de la manifestation, p. 684.

${ }^{56}$ Cf. Idem, p. 685. 
distante de nós do que o acontecido ontem" afirma ele. ${ }^{57}$ Conforme Henry esta constatação de Eckhart significa a impossibilidade de encontrar qualquer referência para medir o afastamento do tempo, isto é, a distensão temporal da existência e mostra que não há relação entre a vida egológica, em sua posse e proximidade absolutas em relação a si, e o eterno escoamento do fluxo temporal. Difícil de ser compreendida, esta afirmação significa que a vida não passa, que ela sempre a mesma.

Filosofia da imanência absoluta, que situa na ipseidade do ego a revelação de si do fundamento absoluto que é vida, a vida individual concebida como afetividade invisível e incognoscível, a fenomenologia material não seria uma nova forma de solipsismo? Como explicar a relação que um tal sujeito concebido a partir da insularidade da sua vida afetiva poderia entreter como o mundo? Como a imanência a si do sujeito pode entrar em relação com a realidade exterior do mundo ? Tais indagações pressupõem que o sujeito deve necessariamente entrar em relação com o mundo, ou melhor, que os dois modos da manifestação, a manifestação na transcendência e na imanência, devem poder se relacionar e que na imanência da sua vida o sujeito não poderia encontrar nenhuma certeza e, principalmente, a certeza do ser exterior. Nesse ponto estamos diante do que talvez venha a ser o que há de mais inusitado e mesmo surpreendente na filosofia de Henry, porque o ser da realidade exterior não deve mais ser demonstrado, como na famosa refutação kantiana do Idealismo, denominada por Heidegger o "escândalo da filosofia". O ser da realidade exterior se experimenta e se revela a partir da prova que eu faço dele sob a mesma modalidade da auto-afecção que caracteriza o exercício de cada um dos poderes da minha vida, inclusive o tocar e o movimento. Através do sentimento de esforço implicado essencialmente na corporalidade e em todas as formas de movimento, por mínimos que sejam tal como piscar os olhos ou respirar, o mundo se revela a nós como contínuo resistente. Assim como Husserl pretendia demonstrar que a certeza do exercício do ato de pensar pelo ego implicava, não apenas a sua existência mas, inclusive a certeza do objeto pensado enquanto seu correlato intencional, da mesma forma Henry pretende, ao modo de um curto-circuito ontológico, transferir o ser-no-mundo heideggeriano para o interior da experiência autoafetante do corpo próprio, pois a exterioridade do mundo não pode determinar, a partir da transcendência da sua estrutura ontológica, nenhuma verdadeira realidade. $\mathrm{O}$ sentido último da epoké husserliana repousava inteiramente, não sobre uma decisão metodológica e livre do fenomenólogo, mas, antes disso, sobre a estrutura prévia do próprio mundo na medida em que a

${ }^{57}$ Idem., p. 478. 
suspensão dos juízos de existência não acarretam nenhuma modificação no mundo reduzido à sua condição fenomenal, e nem mesmo é uma pressuposição para pensá-lo em sua condição de possibilidade. "O único ser existente de uma maneira absoluta", afirma Husserl, é a consciência ${ }^{58}$. Assim, a rejeição do conceito de mundo é, na verdade, a de um absoluto transcendente, exterior à vida, a rejeição da exterioridade, não por um sujeito encerrado em si mesmo, mas por causa da sua incapacidade em determinar a essência da realidade. A efetividade fenomenológica pertence portanto a toda vida individual e ao fundamento através do qual o indivíduo é dado a si mesmo como ipseidade de maneira originária. "Fazendo a prova de si mesmo, o indivíduo é posse de si mesmo (que é sua vida)" ${ }^{59}$

Para terminar com a certeza de não ter tido oportunidade de explorar toda a riqueza do pensamento de Michel Henry, pensamento que representa, seguramente, a vanguarda da fenomenologia contemporânea - tal a dimensão fundamental desse continente quase intacto, teoricamente falando, descoberto pela fenomenologia material - digamos que o transcendental henrineano não pode ser um objeto, conceito ou mesmo idéia, se ele é a raiz da atividade constituinte exercida por um ego, como sabemos após o cartesianismo. Todo o problema consiste em estabelecer as condições nas quais se dá a solidariedade pressentida por quase todo pensamento clássico, entre o homem e o ser, se o pensamento, a razão, a consciência, não são a realidade. A vida, afirmou Marx na Ideologia Alemã, segundo uma célebre formulação, "determina a consciência”. O que um homem é coincide com o modo como vive sua vida, não com o modo que ela a representa ou interpreta na sua consciência. ${ }^{60}$

E a vida se essencializa a cada vez, em cada indivíduo, como a ipseidade própria do ser. A presença do ego a si no cogito, originariamente compreendido como uma fenomenologia material, antes que tal originalidade fosse definitivamente sepultada pelo monismo ontológico, não é a presença a si do pensamento senão enquanto esta presença se faz através da presença da vida no pensamento como poder que se auto-afeta, e assim já sempre adveio a si mesmo. A essência do pensar é o eu penso, não porque me penso pensante no pensamento pensado, ao modo de uma reflexão, mas porque eu sou. O ser do ego, sua vida interior, é a essência do pensamento. " $E u$ sou

\footnotetext{
${ }^{58}$ Cf. Logique formelle et transcendantale. Trad. Suzanne Bachelard, Paris: PUF, 1965, § I03, p. 361.

${ }^{59}$ CF. Incarnation: une philosophie de la chair. Paris: Seuil, 1998, p. 261.

60 O que vale também para a história. Por isso Marx, criticando os historiadores das "idéias", isto é, aqueles que pretendem investigar uma época histórica se apoiando no que ela pensa de si mesma, ao invés de investigar o modo como os homens daquela época viveram e que explica o conteúdo e forma do seu pensamento, da sua "consciência", afirma que inclusive os "comerciantes sabem que não se deve compreender uma homem por aquilo que ele diz de si mesmo". Ideologia Alemã. Porto: Ideologia Alemã. Porto: Editorial Presença, 1978.
} 
explicita simplesmente a condição ontológica de possibilidade do eu penso" ${ }^{61}$, condição, evidentemente, prévia. "Um pensamento que (se) pensa deve”, nesse ato e para poder efetuá-lo, "já ser" antes da reflexão. ${ }^{62}$

\footnotetext{
${ }^{61}$ PRIENTE, Jean-Claud, "Problèmes logiques du cogito". In: Le Discurs et sa méthode, p. 266

62 MARION, J-L. J.-L. M., "La Situation métaphysique du "Discours" IN: Le Discours, op. cit., p. 386.
} 


\section{Referências bibliográficas}

CHAMBON, Roger. Le Monde comme perception et réalité. Paris: Vrin, 1974. DERRIDA, J. A Voz e o fenômeno. Trad. Lucy Magalhães. Rio: Zahar, 1994.

GRANEL, G. Le sens du temps et de la perception chez Husserl. Paris: Gallilé, 1968. GIOVANNANGELI, D. La passion de I'origine; recherches sur I'eshétique transcendantale e la phénoménologie. Paris: Galilée, 2002.

HUSSERL, E. Idées Directrices pour une phénomélogie; introduction générale a la phénoménologie pure. Paris: Gallimard, 1950. . Recherches Logique. Paris: PUF, 1969.

1965. . Logique formelle et transcendantale. Trad. Suzanne Bachelard. Paris: PUF,

HENRY, M. L'essence de la manifestation. Paris: PUF, 1990. . Incarnation: une philosophie de la chair. Paris: Seuil, 1998.

. Philosophie et phénoménologie du corps. Essai sur l'ontologie biranienne. Paris: PUF, 1965. 308p.

_. Généalogie de la psychanalyse. Le commecement perdu. Paris: PUF, 1985. 398p.

. "Descartes et la question de la technique". In: Le discurs et sa méthode, N. Grimaldi et J.-L. Marion (Org.), Paris: PUF, 1987, p. 285-302. . Voir L'Invisible: sur Kandinsky. Paris: François Bourin, 1988. . Phénoménologie matérielle. Paris: PUF, 1990.

HEIDEGGER, M. Lo ser y el tiempo. Trad. José Gaos. México: Fondo de cultura económica, 1987.

1966.

. Lettre sur l'humanisme. Trad. R. Munier. In: Question III. Paris: Gallimard,

LAOUREUX, S. L'Immanence à la limite; recherches sur la phénoménologie de Michel Henry. Paris: CERF, 2005.

LAUER, Q. Phénoménologie de Husserl. Paris: PUF, 1955.

MERLEAU-PONTY, M. Phénoménologie de la Perception. Paris: Gallimard, 1945. . Résumés de cours (1952-1960), Paris: Gallimard, 1968. . Le visible e le invisible. Paris: Gallimard, 1964.

SARTRE, J.P. L'Être et le néant. Paris: Gallimard, 1982.

E-mail: josefurtado1956@hotmail.com

Recebido: 04/2008

Aprovado: $11 / 08$ 